\title{
Requirement of Translation But Not Transcription for the Maintenance of Long-Term Depression in the CA1 Region of Freely Moving Rats
}

\author{
Denise Manahan-Vaughan, ${ }^{1}$ Alexander Kulla, ${ }^{1}$ and J. Uwe Frey ${ }^{2}$ \\ 1 Johannes Mueller Institute for Physiology, Synaptic Plasticity Research Group, Humboldt University Medical Faculty \\ (Charité), D-10115 Berlin, Germany, and 2Leibniz Institute for Neurobiology, Department of Neurophysiology, D-39008 \\ Magdeburg, Germany
}

\begin{abstract}
Hippocampal long-term depression (LTD) comprises a persistent reduction in synaptic strength that can be induced in the CA1 region by repeated low-frequency stimulation (LFS). Previous studies have demonstrated that hippocampal long-term potentiation requires de novo protein synthesis. Whether hippocampal LTD is also protein synthesis-dependent is not known. In this study, we investigated if the previous administration of translation inhibitors (anisomycin or emetine) or a transcription inhibitor (actinomycin-D) influenced the profile of LTD in freely moving adult Wistar rats. Seven- to 8-week-old animals underwent chronic implantation of a recording electrode in the CA1 stratum radiatum and a stimulation electrode in the Schaffer collateral/ commissural fiber pathway. A cannula was implanted in the ipsilateral cerebral ventricle to enable drug administration. Experiments were commenced $10 \mathrm{~d}$ after the implantation proce-
\end{abstract}

dure. Immediately after application of LFS (1 Hz, 900 pulses) robust LTD was seen that persisted for $>8 \mathrm{hr}$ in control animals. Application of anisomycin $(240 \mu \mathrm{g} / 5 \mu \mathrm{l})$ emetine $(240 \mu \mathrm{g} / 5 \mu \mathrm{l})$ before LFS prevented the expression of LTD or $\sim 4.5 \mathrm{hr}$ after LFS. Previous administration of actinomycin D $(72 \mu \mathrm{g} / 12 \mu \mathrm{l})$ had no effect on the expression of LTD. None of the compounds elicited significant effects on basal synaptic transmission when administered in the absence of LFS. These data suggest that LTD in the CA1 region in vivo is protein synthesis-dependent. Furthermore, persistent LTD can be established through the translation of existing mRNA, whereas de novo mRNA transcription does not appear to be necessary.

Key words: actinomycin D; anisomycin; long-term depression; Wistar; hippocampus; protein synthesis; mRNA; transcription; translation
Hippocampal long-term depression (LTD) comprises a persistent functional decrease in synaptic transmission that occurs as a consequence of patterned stimulation of afferent fibers (Bear and Malenka, 1994). As is the case with hippocampal long-term potentiation (LTP), it is dependent on intracellular calcium mobilization, through for example, calcium entry via NMDA receptor channels (Dudek and Bear, 1992; Mulkey and Malenka, 1992) and activation of metabotropic glutamate receptors (mGluRs) (Huang et al., 1997; Manahan-Vaughan, 1997). The relative intracellular concentration of calcium is likely to be a crucial determinant of the form of synaptic plasticity subsequently expressed (Artola and Singer, 1993).

It has been suggested that the mechanisms underlying LTD expression, in conjunction with the mechanisms of LTP, are responsible for information storage by the hippocampus (Bear, 1996). Furthermore, hippocampal LTP and LTD may be associated with specific forms of explicit memory in the cerebral cortex. It has been demonstrated that distinct hippocampus-associated memory storage occurs in phases (Grecksch and Matthies, 1980; Grecksch et al., 1980). This has also shown to be the case with regard to hippocampal LTP, in which late LTP can be dissociated from short-term potentiation (STP) (which lasts for minutes) and early LTP (which lasts for up to $4 \mathrm{hr}$ ) by means of protein synthesis inhibitors or inhibitors of protein kinase A (Krug et al., 1984; Frey et al., 1988, 1993, 1996; Otani et al., 1989; Matthies et al., 1990). Recently,

\footnotetext{
Received April 25, 2000; revised Aug. 25, 2000; accepted Aug. 29, 2000.

This work was supported by Deutsche Forschungsgemeinschaft Grant SFB 515/B8 to D.M.-V. We acknowledge the back-up support of Ms. S. Vieweg, Dr. K.-H Braunewell, and Ms. K. Schuetz.

Correspondence should be addressed to Dr. Denise Manahan-Vaughan, Johannes Mueller Institute for Physiology, Synaptic Plasticity Research Group, Humboldt University Medical Faculty (Charité), D-10115 Berlin, Germany. E-mail: denise.manahanvaughan@charite.de.

Copyright (C) 2000 Society for Neuroscience $0270-6474 / 00 / 208572-05 \$ 15.00 / 0$
}

hippocampal LTD, which endures for many days, has been demonstrated in freely moving rats (Manahan-Vaughan and Braunewell, 1999). This form of LTD also exists in phases: an NMDA receptor-dependent phase of short-term depression (STD), which lasts for $\sim 1 \mathrm{hr}$, and an mGluR-dependent phase, which becomes evident immediately after the NMDA receptor phase and which might resemble the stage of early LTP (Manahan-Vaughan, 1997).

Information storage in the form of a long-term reduction in synaptic plasticity may be accompanied by protein synthesisdependent synaptic modifications. First, indications that the maintenance of LTD may depend on protein synthesis came from studies in the cerebellum, in which the application of protein synthesis inhibitors prevented late LTD (Linden, 1996; Levenes et al., 1998). Whether hippocampal LTD also has a protein synthesisdependent phase has not been established to date. This study therefore set about to examine whether inhibitors of mRNA translation and transcription influence the expression of hippocampal LTD in freely moving rats.

\section{MATERIALS AND METHODS}

Surgical preparation. Seven- to 8-week-old male Wistar rats were prepared as described previously (Manahan-Vaughan, 1997). Briefly, under sodium pentobarbitone anesthesia (Nembutal; $40 \mathrm{mg} / \mathrm{kg}$, i.p.), animals underwent implantation of a monopolar recording and a bipolar stimulating electrode (made from $0.1 \mathrm{~mm}$ diameter Teflon-coated stainless steel wire). A drill hole was made (1-mm-diameter) for the recording electrode $(2.8 \mathrm{~mm}$ posterior to bregma, $1.8 \mathrm{~mm}$ lateral to the midline), and a second drill hole $(1 \mathrm{~mm}$ diameter, $3.1 \mathrm{~mm}$ posterior to bregma, $3.1 \mathrm{~mm}$ lateral to the midline) was made for the stimulating electrodes (coordinates based on Paxinos and Watson, 1986). The dura was pierced through both holes, and the recording and stimulating electrodes were lowered into the CA1 stratum radiatum and the Schaffer collaterals, respectively. Recordings of evoked field potentials via the implanted electrodes were taken throughout surgery. A cannula was implanted in the lateral cerebral ventricle $(0.08 \mathrm{~mm}$ posterior to bregma; midline: $1.6 \mathrm{~mm}$ lateral to the midline). Once verification of the location of the electrodes was complete, the entire assembly was sealed and fixed to the skull with dental acrylic (Paladur; Heraeus 
Kulzer, GmbH, Wehrheim, Germany). The animals were allowed $10 \mathrm{~d}$ to recover from surgery before experiments were conducted. Twenty-four hours before the commencement of the experiments, animals were placed in the recording chamber with ad libitum access to food and water, to allow familiarization to occur. Throughout the experiments the animals could move freely within the recording chamber $(40 \times 40 \times 40 \mathrm{~cm})$, as the implanted electrodes were connected by a flexible cable and swivel connector to the stimulation unit and amplifier. Aside from the insertion of the connector cable and injection cannula at the start of the experiment, disturbance of the animals was kept to an absolute minimum. Throughout the experiments the electroencephalogram of each animal was continuously monitored.

Measurement of evoked potentials. The field EPSP (fEPSP) slope was used as a measure of excitatory synaptic transmission in the CA1 region. To obtain these measurements, an evoked response was generated in the stratum radiatum by stimulating at low frequency $(0.025 \mathrm{~Hz})$ with single biphasic square wave pulses of $0.1 \mathrm{msec}$ duration per half wave, generated by a constant current isolation unit. For each time point measured during the experiments, five records of evoked responses were averaged. fEPSP was measured as the maximal slope through the five steepest points obtained on the first negative deflection of the potential. By means of input-output curve determination, the maximum fEPSP was found, and during experiments all potentials used as baseline criteria were evoked at a stimulus intensity that produced $40 \%$ of this maximum. LTD was induced by low-frequency stimulation (LFS) at $1 \mathrm{~Hz}$ (900 pulses). Only fEPSPs in which $40 \%$ of the input-output maximum could be evoked using a stimulation intensity of $\leq 150 \mu \mathrm{A}$ were used for this study. If the fEPSPs fulfilled this criterion, LTD was consistently evoked throughout the experiments. Ambient conditions were kept constant to prevent environmental influences on behavioral state that might affect the LTD expressed (Manahan-Vaughan and Braunewell, 1999; Manahan-Vaughan, 2000a).

Compounds and drug treatment. For injection, anisomycin and emetine ( $2.4 \mathrm{mg}$; Sigma-Aldrich) were first dissolved in $15 \mu \mathrm{l}$ of $\mathrm{HCl}$ solution $(1 \mathrm{~N})$ and then treated with $1 \mathrm{~N} \mathrm{NaOH}$ to create a $\mathrm{pH}$ of 7.0. The solutions were subsequently made up to a $50 \mu \mathrm{l}$ volume with $0.9 \%$ sodium chloride. The animal was injected with $5 \mu \mathrm{l}$ of this solution $(240 \mu \mathrm{g})$ over a 6 min period via a Hamilton syringe. Actinomycin-D (Sigma-Aldrich) was fully dissolved in $0.9 \%$ sodium chloride. $\mathrm{A} \mathrm{pH}$ of 7.0 was established using $1 \mathrm{~N}$ $\mathrm{NaOH}$. The total amount injected was $72 \mu \mathrm{g} / 12 \mu \mathrm{l}$ over a 6 min injection duration. Throughout the experiments, drugs or vehicle were applied into the lateral cerebral ventricle via an injection cannula that was inserted through the surgically implanted outer cannula. In all experiments, drug or vehicle injection was administered after the observation of basal synaptic transmission for $30 \mathrm{~min}$. Two hours later LFS was applied. Evoked responses were then monitored for a further $8 \mathrm{hr}$. In case of control experiments in which no LFS was given, evoked responses were monitored for a total of $10 \mathrm{hr}$ after drug or vehicle injection.

Data analysis. The baseline fEPSP data were obtained by averaging the response to stimulation of the Schaffer collaterals, to obtain five sweeps at $40 \mathrm{sec}$ intervals, every $5 \mathrm{~min}$ over a period of $30 \mathrm{~min}$. Drug or vehicle injections were then applied, and three further measurements at $5 \mathrm{~min}$ intervals were taken, followed by recordings at 15 min intervals for $2 \mathrm{hr}$. At this point LFS was given, and three measurements at 5 min intervals were then taken and followed by recordings at $15 \mathrm{~min}$ intervals for $8 \mathrm{hr}$. The same protocol for observation of evoked potentials was followed in which no LFS was given. The data were then expressed as mean percentage of preinjection baseline fEPSP reading \pm SEM. Statistical significance was estimated using the Mann-Whitney $U$ test. The probability level interpreted as statistically significant was $* p<0.05$.

\section{RESULTS}

\section{Hippocampal long-term depression in freely moving rats requires protein translation}

When LFS (900 pulses at $1 \mathrm{~Hz}$ ) was applied via the Schaffer collateral- commissural pathway to the stratum radiatum of the CA1 region, an LTD of the fEPSP was generated that was still present $8 \mathrm{hr}$ after LFS was given (data not shown). No change in the profile of LTD was seen when a vehicle injection was applied 2 hr before LFS via a cannula implanted in the lateral cerebral ventricle $(n=6$; Fig. $1 A$ ). The fEPSP 5 min after LFS was $42 \pm 6 \%$ of preinjection fEPSP baseline values, and LTD was still present after $8 \mathrm{hr}$. This type of LTD has been shown to persist of over $7 \mathrm{~d}$ in this rat strain (Manahan-Vaughan and Braunewell, 1999).

The involvement of protein translation in the induction of hippocampal LTD in vivo was examined using the reversible translation inhibitor anisomycin, and emetine. When anisomycin was applied $2 \mathrm{hr}$ before LFS, in a concentration that effectively blocked LTP in vivo (240 $\mu \mathrm{g} / 5 \mu \mathrm{l}$ injection volume; data not shown), a significant inhibition of LTD occurred (Fig. 1A). Five minutes
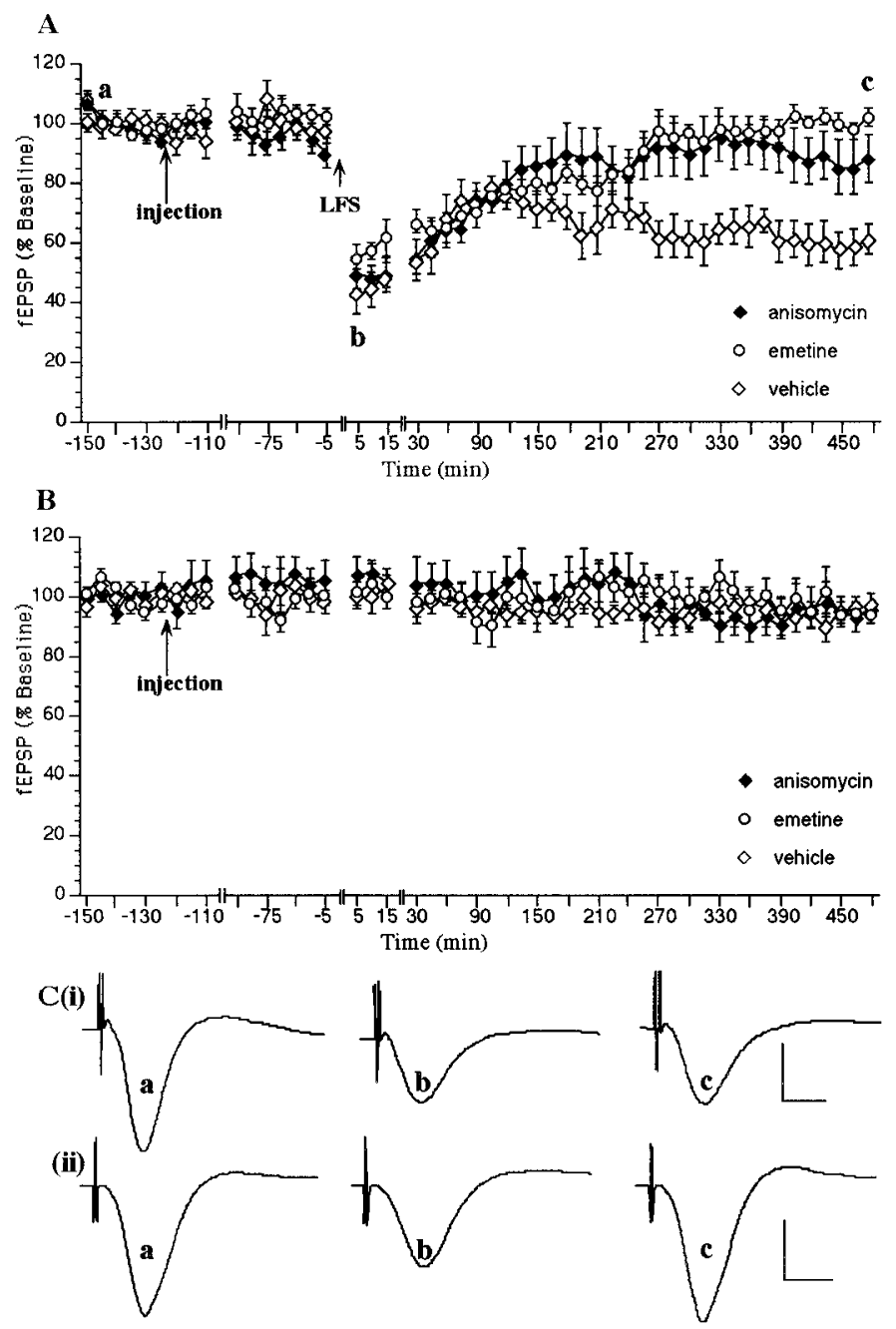

Figure 1. LTD in the CA1 region in vivo is dependent on protein translation. $A$, A low-frequency train $(L F S)$ in the presence of a vehicle injection $(n=6)$ results in a robust LTD that persists for $>8 \mathrm{hr}$. Injection of the protein translation inhibitors anisomycin $(240 \mu \mathrm{g} / 5 \mu \mathrm{l} ; n=10)$ or emetine $(240 \mu \mathrm{g} / 5 \mu \mathrm{l} ; n=7) 2 \mathrm{hr}$ before LFS completely inhibits the expression of LTD from $\sim 4.5 \mathrm{hr}$ after LFS. B, Anisomycin $(240 \mu \mathrm{g} / 5 \mu \mathrm{l} ; n=6)$ or emetine $(240 \mu \mathrm{g} / 5 \mu \mathrm{l} ; n=7)$ have no effect on basal synaptic transmission compared to vehicle-injected controls $(n=6)$. $C$, Original analog traces showing evoked responses in the CA1 region at three time points: preinjection, $t=5 \mathrm{~min}$ and $t=8 \mathrm{hr}$ after LFS, in $(i)$ a vehicle-injected animal and (ii) an animal injected with anisomycin $(240 \mu \mathrm{g} / 5 \mu \mathrm{l})$. Calibration: $5 \mathrm{msec}$, $5 \mathrm{mV}$. Line breaks indicate change in time scale.

after LFS, the fEPSP in the anisomycin group was $48.8 \pm 4.54 \%$ of preinjection fEPSP baseline values $(n=10)$. This depression was maintained until $t=270$ min after LFS when a significant recovery of fEPSP values in the anisomycin group was noted. Thus, at $t=$ 270 min after LFS, the values of the control group were statistically different when compared with anisomycin-treated animals (60.8 \pm $5.99 \%$ vs $91.7 \pm 9.52 \%$ ( $U$ test, $p<0.05)$.

The same concentration of anisomycin $(240 \mu \mathrm{g} / 5 \mu \mathrm{l}$ injection volume; $n=6$ ) had no significant effect on hippocampal basal synaptic transmission when compared to vehicle-treated control animals $(n=6$; Fig. $1 B)$.

When emetine was administered $2 \mathrm{hr}$ before LFS, in a concentration which was reported to significantly block hippocampal LTP in vivo (240 $\mu \mathrm{g}$; Otani et al., 1989), a significant inhibition of LTD occurred that was similar to that seen with anisomycin (Fig. 1A). Five minutes after LFS, the fEPSP in the emetine group was $54.9 \pm 3.74 \%$ of pre-injection fEPSP baseline values $(n=7)$. This 

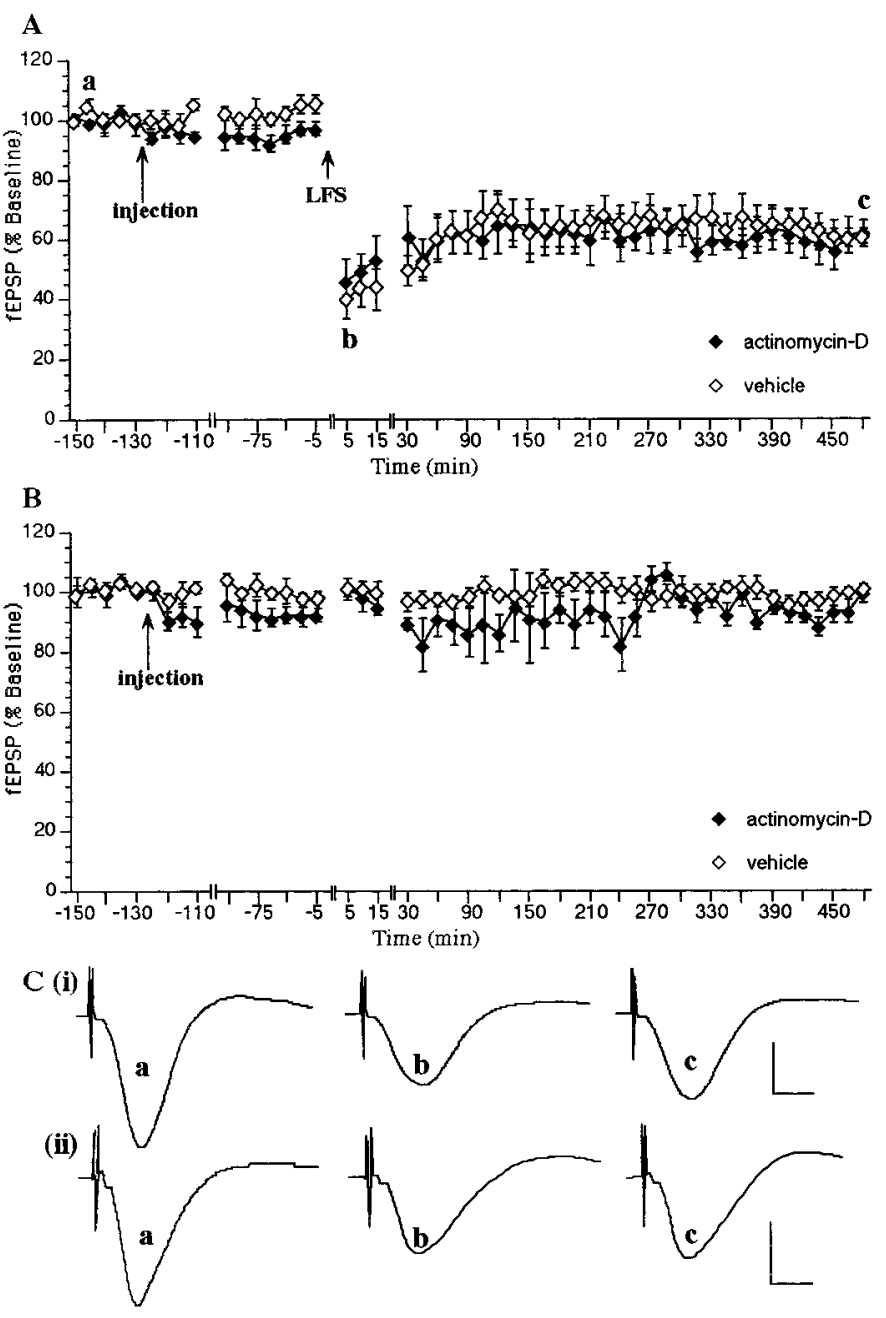

Figure 2. LTD in the CA1 region in vivo is not dependent on transcription. $A$, A low-frequency train $(L F S)$ in the presence of vehicle $(n=6)$ results in a robust LTD that persists for $>8 \mathrm{hr}$. Injection of the protein transcription inhibitor actinomycin-D $(72 \mu \mathrm{g} / 12 \mu \mathrm{l} ; n=6) 2 \mathrm{hr}$ before LFS has no effect on the expression of LTD compared to vehicle-treated animals. $B$, Actinomycin-D $(72 \mu \mathrm{g} / 12 \mu \mathrm{l} ; n=6)$ has no effect on basal synaptic transmission compared to vehicle-injected controls $(n=6)$. $C$, Original analog traces showing evoked responses in the CA1 region at three time points: preinjection, $t=5 \mathrm{~min}$ and $t=8 \mathrm{hr}$ after LFS, in $(i)$ a vehicleinjected animal and (ii) an animal injected with actinomycin-D (72 $\mu \mathrm{g} / 12$ $\mu \mathrm{l} ; n=6$ ). Calibration: $5 \mathrm{msec}, 5 \mathrm{mV}$. Line breaks indicate change in time scale.

depression was maintained until $t=255 \min$ after LFS when a significant recovery of fEPSP values in the emetine group was observed. Thus, at $t=255 \mathrm{~min}$ after LFS, the values of the emetine-treated group $(90.8 \pm 3.77 \%)$ were statistically different when compared to controls $(67.8 \pm 4.64 \% ; n=6$; $U$ test, $p<0.05)$.

Emetine $(240 \mu \mathrm{g} / 5 \mu \mathrm{l}$ injection volume; $n=7)$ had no significant effect, however, on hippocampal basal synaptic transmission when compared to vehicle-treated control animals ( $n=6$; Fig. $1 B)$.

\section{Hippocampal long-term depression in freely moving rats does not require transcription}

To investigate the involvement of transcription in hippocampal LTD in vivo, the transcription inhibitor actinomycin-D was used. This concentration significantly inhibits hippocampal late LTP in vivo with regard to population spike amplitude (whereas fEPSP slope remains largely unchanged) (Frey et al., 1996). Furthermore, Otani et al. (1989) demonstrated a 95\% inhibition of hippocampal
mRNA synthesis when $60 \mu \mathrm{g}$ of actinomycin-D was injected into the lateral cerebral ventricle. Thus, an effective inhibition of transcription can be expected at the higher dose, $72 \mu \mathrm{g}$, used in our study.

When actinomycin-D (72 $\mu \mathrm{g} / 12 \mu \mathrm{l}$ injection volume) was administered $2 \mathrm{hr}$ before LFS, no significant modification of the profile of LTD occurred (Fig. $2 A$ ). Five minutes after LFS fEPSP values were $38.8 \pm 6.47 \%$ of preinjection fEPSP baseline values in controls $(n=6)$ and $46.3 \pm 6.52 \%$ in actinomycin-D-treated animals $(n=6)$. Eight hours after administration of LFS, fEPSP values were $59.5 \pm 3.22 \%$ and $61.8 \pm 4.23 \%$ in vehicle- and actinomycintreated animals, respectively.

The same concentration of actinomycin $(72 \mu \mathrm{g} / 12 \mu \mathrm{l}$ injection volume) had no effect on hippocampal basal synaptic transmission when compared to vehicle-treated control animals (Fig. 2B).

\section{DISCUSSION}

The data from this study support the hypothesis that LTD in the CA1 region of freely moving rats is dependent on protein synthesis. Furthermore, the protein synthesis concerned appears to be performed using existing mRNA, whereas transcription of new mRNA does not appear to be necessary for the time period investigated ( 8 $\mathrm{hr})$. The possibility that the transcription and translation inhibitors used had toxic effects within the experimental time course studied can be minimized because no significant effect on basal synaptic transmission elicited by test-pulse stimulation was noted for either anisomycin, emetine, or actinomycin-D. However, subtle unspecific effects, which are not expressed as immediate changes of electrophysiological responses, cannot be excluded.

Interestingly, as is the case with hippocampal LTP, LTD appears to be characterized by distinct phases that mechanistically mirror those described for memory formation in mammals (Matthies et al., 1990). Thus, together with the previously described NMDA receptor and mGluR-dependent STD (Dudek and Bear 1992; Mulkey and Malenka, 1992; Huang et al., 1997; Manahan-Vaughan, 1997, $1998,2000 \mathrm{~b})$, which is associated with subsequent activation of calcium calmodulin kinase II, activation of calcineurin, and disinhibition of protein phosphatase 1 (Bear and Malenka, 1994), hippocampal LTD is also accompanied by a protein synthesisdependent phase that becomes evident $\sim 4 \mathrm{hr}$ after LFS. Given NMDA receptor-dependent kinase regulation (Norman et al., 2000) and the mGluR-dependent involvement of protein kinase A, C (Kameyama et al., 1998; Huang et al., 1999a,b), and G (Wu et al., 1998) in hippocampal LTD, together with the reported requirement of kinases such as protein kinase A for protein synthesis in other forms of hippocampal plasticity (Frey et al., 1993; Nayak et al., 1998), it is quite possible that these LTD phases are interrelated. Recently, it was shown that the chemical induction of CA1 LTD in vitro by application of a group I mGluR agonist depends on protein synthesis in the form of mRNA translation (Huber et al., 2000). LFS-induced CA1 LTD in vivo is dependent on mGluR activation (Manahan-Vaughan, 1997), suggesting a further link in these processes.

Hippocampal LTD, as determined by changes in fEPSP, i.e., the synaptic response, does not appear to require de novo RNA synthesis. Thus, application of actinomycin-D did not alter the profile of LTD subsequently expressed. Within the present study a comparison was not made with the effectiveness of actinomycin-D in blocking CA1 LTP in vivo. Thus, one cannot rule out the possibility that the failure of actinomycin-D to block LTD arose as a result of insufficient drug concentration. However, Otani et al. (1989) reported a 95\% inhibition of hippocampal mRNA synthesis when 60 $\mu \mathrm{g}$ of actinomycin-D was injected into the rat lateral cerebral ventricle. Thus, an effective inhibition of transcription should be expected at the higher dose, $72 \mu \mathrm{g}$, used in the present study. Interestingly, our data are in accordance with our earlier report showing that LTP in the CA1 region, if determined by changes in fEPSP responses, seems not to require transcription during the first 
$8 \mathrm{hr}$ after LTP induction (Frey et al., 1996). This finding indicates that LTD and LTP may use common mechanisms for consolidation. However, the latter results are in contrast to similar experiments in the hippocampal CA1 in which the application of mRNA synthesis inhibitors blocked the induction of late LTP when also measured as changes in fEPSP responses (Nguyen et al., 1994). These contradictory findings could be attributable to nonspecific effects of actinomycin-D caused by the presence of the drug during induction of LTP in the latter in vitro experiments.

The finding that transcription-dependent protein synthesis is not required for LTD in vivo suggests, however, that mRNA that is already present within the dendrite of the activated synapses is used to encode the proteins that enable persistent LTD. Dendritic protein synthesis has been described for hippocampal neurons (Steward, 1994, 1997). Furthermore, mRNA has been localized at the base of hippocampal dendritic spines (Steward and Levy, 1982; Kleiman et al., 1990; Martone et al., 1996; Tiedge and Brosus, 1996). Recently, chemical induction of CA1 LTD via a group I metabotropic glutamate receptor agonist was shown to depend on dendritic mRNA (Huber et al., 2000). Thus, the possibility that hippocampal LTD uses local mRNA for protein synthesis exists. Indeed, mRNA for proteins that are postulated to play a role in LTD have been identified near dendritic spines, such as certain subunits for the glutamate receptor and $\alpha$ CAMkinase II (Steward, 1997).

It cannot be ruled out of course, that proteins essential for LTD are synthesized either in the soma and then transported along the dendrite to the activated target synapses, or synthesized in specific dendritic compartments that are relatively far away from the activated synapse. A corollary of this is the possibility that a synaptic tag (Frey and Morris, 1997, 1998) is involved in the consolidation of LTD. It has already been demonstrated for hippocampal LTP that synapses activated by tetanic stimulation can recruit proteins, whose synthesis has been initiated at other sites within the neuron, and thereby enable stabilization of long-term potentiation. A similar mechanism may be used in LTD. Translation of mRNA at the soma could then result in protein transport through the neuron that would then be sequestered by the synapses that were activated by LFS.

Recently it was demonstrated that hippocampal LTD may be associated with novelty acquisition and recognition in rats (Manahan-Vaughan and Braunewell, 1999), this finding adds weight to earlier postulations that hippocampal LTD may be associated with learning and memory in mammals (Bear, 1996; Bear and Abraham, 1996). Given existing evidence for a role for protein synthesis in hippocampus-based learning phenomena (Grecksch and Matthies, 1980; Grecksch et al., 1980; Mizumori et al., 1985; Quevedo et al., 1999), these findings, together with the current data supporting the involvement of protein synthesis in LTD consolidation, prompt a revision in current thinking that favors LTP as the cellular basis of learning and memory. Rather it may be the case that both forms of synaptic plasticity serve different forms of learning and memory.

In conclusion, the current data show that, as is the case with LTP, LTD in the CA1 region of freely moving rats is protein synthesisdependent. Transcription of new mRNA is apparently not necessary for LTD consolidation within the first $8 \mathrm{hr}$ after its induction, rather existing mRNA is translated to create the proteins required. These data offer the first evidence to demonstrate a role for protein synthesis in hippocampal LTD, and given the role of protein synthesis in learning and memory phenomena, point to a significant involvement of this form of synaptic plasticity in information storage in the mammalian brain.

\section{REFERENCES}

Artola A, Singer W (1993) Long-term depression of excitatory synaptic transmission and its relationship to long-term potentiation. Trends Neurosci 16:480-487.

Bear MF (1996) A synaptic basis for memory storage in the cerebral cortex. Proc Natl Acad Sci USA 93:13453-13459.
Bear MF, Abraham WC (1996) Long-term depression in the hippocampus. Annu Rev Neurosci 19:437-462.

Bear MF, Malenka RC (1994) Synaptic plasticity: LTP and LTD. Curr Opin Neurobiol 4:389-399.

Dudek SM, Bear MF (1992) Homosynaptic long-term depression in area CA1 of hippocampus and the effects of NMDA receptor blockade. Proc Natl Acad Sci USA 89:4363-4367.

Frey U, Morris RGM (1997) Synaptic tagging and long-term potentiation. Nature 385:533-536.

Frey U, Morris RGM (1998) Weak before strong: dissociating synaptic tagging and plasticity-factor accounts of late-LTP. Neuropharmacology 37:545-552.

Frey U, Krug M, Reymann KG, Matthies H (1988) Anisomycin, an inhibitor of protein synthesis, blocks late phases of LTP phenomena in the hippocampal CA1 region in vitro. Brain Res 452:57-65.

Frey U, Huang YY, Kandel ER (1993) Effects of cAMP simulate a late stage of LTP in hippocampal CA1 neurons. Science 260:1661-1664.

Frey U, Frey S, Schollmeier F, Krug M (1996) Influence of actinomycin D, a RNA synthesis inhibitor, on long-term potentiation in rat hippocampal neurons in vivo and in vitro. J Physiol (Lond) 490:703-711.

Grecksch G, Matthies H (1980) Two sensitive periods for the amnesic effect of anisomycin. Pharmacol Biochem Behav 12:663-665.

Grecksch G, Ott T, Matthies H (1980) The effect of intrahippocampally applied anisomycin on the retention of brightness discrimination in rats. Behav Neural Biol 29:281-288.

Huang LQ, Rowan MJ, Anwyl R (1997) mGluR II agonist inhibition of LTP induction, and mGluR II antagonist inhibition of LTD induction, in the dentate gyrus in vitro. NeuroReport 8:687-693.

Huang L, Killbride J, Rowan MJ, Anwyl R (1999a) Activation of mGluRII induces LTD via activation of protein kinase A and protein kinase C in the dentate gyrus of the hippocampus in vitro. Neuropharmacology 38:73-83.

Huang LQ, Rowan MJ, Anwyl R (1999b) Role of protein kinases A and $\mathrm{C}$ in the induction of mGluR-dependent long-term depression in the medial perforant path of the rat dentate gyrus in vitro. Neurosci Lett 274:71-74.

Huber KM, Kayser MS, Bear MF (2000) Role for rapid dendritic protein synthesis in hippocampal mGluR-dependent long-term depression. Science 288:1254-1257.

Kameyama K, Lee HK, Bear MF, Huganir RL (1998) Involvement of a postsynaptic protein kinase A substrate in the expression of homosynaptic long-term depression. Neuron 21:1163-1175.

Kleiman R, Banker G, Steward O (1990) Differential subcellular localizations of particular mRNAs in hippocampal neurons in culture. Neuron 5:821-830.

Krug M, Lossner B, Ott T (1984) Anisomycin blocks the late phase of long-term potentiation in the dentate gyrus of freely moving rats. Brain Res Bull 13:39-42.

Levenes C, Daniel H, Crépel F (1998) Long-term depression of synaptic transmission in the cerebellum: cellular and molecular mechanisms revisited. Prog Neurobiol 55:79-91.

Linden DJ (1996) A protein synthesis-dependent late phase of cerebellar long-term depression. Neuron 17:483-490.

Manahan-Vaughan D (1997) Group 1 and 2 metabotropic glutamate receptors play differential roles in hippocampal long-term depression and long-term potentiation in freely moving rats. $J$ Neurosci 17:3303-3311.

Manahan-Vaughan D (1998) Priming of group 2 metabotropic glutamate receptors facilitates induction of long-term depression in the dentate gyrus of freely moving rats. Neuropharmacology 37:1459-1464.

Manahan-Vaughan D (2000a) Long-term depression in freely moving rats is dependent upon strain variation, induction protocol and behavioral state. Cereb Cortex 10:482-487.

Manahan-Vaughan D (2000b) Group 3 metabotropic glutamate receptors modulate long-term depression in the hippocampal CA1 region of freely moving rats. Neuropharmacology 39:1952-1958.

Manahan-Vaughan D, Braunewell KH (1999) Novelty acquisition is associated with induction of hippocampal long-term depression. Proc Natl Acad Sci USA 96:8739-8744.

Martone WE, Pollack JA, Jones YZ, Ellisman MH (1996) Ultrastructural localization of dendritic messenger RNA in adult rat hippocampus. J Neurosci 16:7437-7446.

Matthies H, Frey U, Reymann K, Krug M, Jork R, Schroeder H (1990) Different mechanisms and multiple stages of LTP. Adv Exp Med Biol 268:359-368.

Mizumori SJ, Rosenzweig MR, Bennett EL (1985) Long-term working memory in the rat: effects of hippocampally applied anisomycin. Behav Neurosci 99:220-232.

Mulkey RM, Malenka RC (1992) Mechanisms underlying induction of homosynaptic long-term depression in area CA1 of the hippocampus. Neuron 9:967-975.

Nayak A, Zastrow DJ, Lickteig R, Zahniser NR, Browning MD (1998) Maintenance of late-phase LTP is accompanied by PKA-dependent increase in AMPA receptor synthesis Nature 394:680-683. 
Nguyen P V, Abel T, Kandel ER (1994) Requirement of a critical period of transcription for induction of a late phase of LTP. Science 265:1104-1107.

Norman ED, Thiels E, Barrionuevo G, Klann E (2000) Long-term depression in the hippocampus in vivo is associated with protein phosphatasedependent alterations in extracellular signal-regulated kinase. J Neurochem 74:192-198.

Otani S, Marshal CJ, Tate WP, Goddard G V, Abraham WC (1989) Maintenance of long-term potentiation in rat dentate gyrus requires protein synthesis but not messenger RNA synthesis immediately posttetanization. Neuroscience 28:519-526.

Paxinos G, Watson C (1986) The rat brain in stereotaxic coordinates, Ed 2. New York: Academic.

Quevedo J, Vianna M R, Roesler R, de-Paris F, Izquierdo I, Rose S P (1999) Two time windows of anisomycin-induced amnesia for inhibitory avoidance training in rats: protection from amnesia by pretraining but not pre-exposure to the task apparatus. Learn Mem 6:600-607.

Steward O (1994) Dendrites as compartments for macromolecular synthesis. Proc Natl Acad Sci USA 91:10766-10768.

Steward O (1997) mRNA localisation in neurons: a multipurpose mechanism? Neuron 18:9-12.

Steward O, Levy WB (1982) Preferential localization of polyribosomes under the base of dendritic spines in granule cells of the dentate gyrus. J Neurosci 2:284-291.

Tiedge H, Brosus J (1996) Translational machinery in dendrites of hippocampal neurons in culture. J Neurosci 16:7171-7181.

Wu J, Wang Y, Rowan MJ, Anwyl R (1998) Evidence for involvement of the cGMP-protein kinase G signaling system in the induction of longterm depression, but not long-term potentiation, in the dentate gyrus in vitro. J Neurosci 18:3589-3596. 